\title{
Preliminary Radiation Shielding Design for BOOMERANG
}

\author{
R. J. Donahue \\ Lawrence Berkeley National Lab
}

June 11, 2003

\begin{abstract}
Preliminary radiation shielding specifications are presented here for the $3 \mathrm{GeV}$ BOOMERANG Australian synchrotron light source project. At this time the bulk shield walls for the storage ring and injection system (100 MeV Linac and $3 \mathrm{GeV}$ Booster) are considered for siting purposes.
\end{abstract}

\section{Introduction}

These estimates were prompted by the BOOMERANG Workshop held at LBNL in October, 2002. BOOMERANG is planned to be a $3 \mathrm{GeV}, 400 \mathrm{~mA} 3^{\text {rd }}$ generation light source with a $20 \mathrm{hr}$ lifetime and $210 \mathrm{~m}$ circumference. This corresponds to a stored beam of $1.75 \times 10^{12} \mathrm{e}^{-}$. Shielding estimates are made for the storage ring. Booster and LINAC shielding estimates will be made elsewhere.

\section{Comparison With Existing/Planned Facilities}

A comparison of the concrete shielding requirements for existing or planned synchrotron facilities is shown in Table 1. They are the Canadian Light Source (CLS - 2.9 GeV, $500 \mathrm{~mA}$ ), the SPEAR3 facility at SLAC (3 GeV, $500 \mathrm{~mA})$, and the Advanced Light Source at LBNL (ALS - 1.9 GeV, 400 $\mathrm{mA}$ ). The 4th column, ALS*, represents the ALS shielding values scaled to $3 \mathrm{GeV}$ and $400 \mathrm{~mA}$ for BOOMERANG.

\section{Assumptions}

All beam loss scenarios are assumed to be roughly the same as those of the LBNL Advanced Light Source (ALS)[1]. The ALS storage ring shield walls were divided into three areas; standard walls ( 8 out of 12 sectors), special walls (3 out of 12 sectors), and injection ( 1 out of 12 sectors). The 
Table 1: Comparison of shielding requirements for existing or planned facilities.

\begin{tabular}{l|llll} 
Location & CLS & SPEAR3 & ALS & ALS* \\
\hline \hline SR Outside Wall & $46 \mathrm{~cm}$ & $61 \mathrm{~cm}$ & $30 / 46 / 61$ & $40 / 56 / 71 \mathrm{~cm}$ \\
SR Inside Wall & 35 & 61 & $30 / 61$ & $40 / 71$ \\
SR Roof & 60 & 30 & $30 / 46$ & $40 / 56$ \\
SR Ratchet & 54 & 91 & $46 / 61$ & $66 / 81$
\end{tabular}

special walls were adjacent to the Booster-to-Storage Ring transfer line while the injection walls were adjacent to the injection septum.

For BOOMERANG no distinction is made between special and injection walls - beam losses and resulting shielding for the injection walls are assumed to apply for the $1 / 3 \mathrm{rd}$ of the storage ring in the injection area.

Beam losses are assumed to be $25 \%$ of the injected beam $\left(2.33 \times 10^{12}\right.$ e- per fill $)$ into the storage ring during injection. Of this, $12.5 \%\left(3 \times 10^{11} \mathrm{e}^{-}\right.$per fill $)$can be lost at any point in the injection area, and the remaining $12.5 \%$ are assumed to be evenly lost around the storage ring.

In addition to injection losses there will be normal beam decay losses. The beam lifetime is $20 \mathrm{hrs}$. Over one $8 \mathrm{hr}$ shift the beam will decay by about 33\%. Therefore over an $8 \mathrm{hr}$ shift distributed losses will be $12.5 \%$ of injected beam $\left(3 \times 10^{11} \mathrm{e}^{-}\right)$and $33 \%$ of stored beam $\left(6 \times 10^{11} \mathrm{e}^{-}\right)$for a total of $9 \times 10^{11} \mathrm{e}^{-}$per shift. The distances of closest approach from the source location is assumed to be $10 \mathrm{~m}$ for the forward directed bremsstrahlung incident on a ratchet wall, and $2 \mathrm{~m}$ for the side walls. These are the distances from the point of beam loss to a point $30 \mathrm{~cm}$ from the outside surface of the shield wall.

No credit is taken for possible self-shielding of accelerator components. The bremsstrahlung target is assumed to be an optimum target that produces the largest doses in the forward direction and also at large angles. No credit is taken for radiations penetrating the shields at slant angles.

Normal density concrete $\left(2.35 \mathrm{~g} / \mathrm{cm}^{3}\right)$ is assumed throughout.

No credit is taken for occupancy factors in reducing the dose rates outside the shield walls.

\section{Criteria}

Two radiation criteria are used:

(1) Under normal operating conditions the dose rate should not exceed $2 \mathrm{mSv}$ (200 mrem) per 2000 hrs (40 hrs x 50 weeks). This corresponds to a dose rate of $1 \mathrm{uSv} / \mathrm{hr}(0.1 \mathrm{mrem} / \mathrm{hr})$.

(2) Assuming an accident condition whereby the entire stored beam is lost at one point, the dose 
Table 2: Concrete requirements for bulk shielding.

\begin{tabular}{l|lll} 
Location & Standard & Special & Injection \\
\hline \hline Outer Wall & $50 \mathrm{~cm}$ & $60 \mathrm{~cm}$ & $60 \mathrm{~cm}$ \\
Inner Wall & 50 & 60 & 60 \\
Ratchet Wall & 50 & 60 & 60 \\
Roof & 35 & 50 & 50
\end{tabular}

to any individual outside the shield wall should not exceed $0.1 \mathrm{mSv}$ (10 mrem) per event.

\section{Analytic Approach}

The SHIELD11 code from SLAC, based on the work of Jenkins[2], is used to estimate dose rate per $\mathrm{e}^{-}$outside the shield. This approach is similar to that of Tesch[3], with the rules of thumb found in Swanson[4] and with the summary provided by Sullivan[5].

Initial runs were performed to determine bulk concrete shield wall thicknesses. These results for 50 $\mathrm{cm}, 60 \mathrm{~cm}$ and $35 \mathrm{~cm}$, as a function of beam angle, are shown in Figs. 1, 2 and 3, respectively. The dashed lines represent the contributions from Giant Dipole Resonance (GDR) neutrons and pseudodeuteron neutron production. GDR neutron production is assumed to be isotropic. Large angle neutron doses are dominated by GDR neutrons. The dotted lines represent bremsstrahlung photons which are highly forward directed. The bulk concrete shielding requirements are summarized in Table 2. Using these shield wall specifications as a starting point supplemental $\mathrm{Pb}$ shielding, if required, will be determined in the next section.

\section{Side Walls - Injection Area}

Inner and outer side walls in the injection area are $60 \mathrm{~cm}$ thick. Normal operation beam loss is $12.5 \%$ of injected beam $\left(3 \times 10^{11} \mathrm{e}^{-}\right.$per fill $)$. To achieve $0.1 \mathrm{mrem} / \mathrm{hr}$ the dose rate through the shield should not exceed $\left(10^{-4} \mathrm{rem} / \mathrm{hr}\right) /\left(3 \times 10^{11} \mathrm{e}-/ 8 \mathrm{hrs}\right)$ or $3 \times 10^{-15} \mathrm{rem} / \mathrm{e}-$. From Fig. 2 the dose rate outside the $60 \mathrm{~cm}$ wall at 90 degrees is $3 \times 10^{-15}$ rem/e- so no supplemental shielding is required for normal operation.

For accidental beam loss we have the stored beam of $1.75 \times 10^{12}$ e- lost at a point. The resulting dose rate is $\left(3 \times 10^{-15} \mathrm{rem} / \mathrm{e}-\right) \times\left(1.75 \times 10^{12} \mathrm{e}-\right)$ or $5 \times 10^{-3}$ rem or about 5 mrem. This is less than the accident criteria of 10 mrem per event so no supplemental shielding is required. 


\section{Side Walls - Standard Area}

Inner and outer side walls in the standard area are $50 \mathrm{~cm}$ thick. Normal beam loss is $9 \times 10^{11}$ e-/shift distributed around the $210 \mathrm{~m}$ circumference. The assumption is made that only an arc of $10 \mathrm{~m}$ will contribute to a persons dose outside the shield wall. Areas larger than this will have to penetrate a large slant thickness. The beam loss is $\left(9 \times 10^{11}\right.$ e- $\left./ 8 \mathrm{hrs}\right) \times 10 \mathrm{~m} / 210 \mathrm{~m}$ or $5.4 \times 10^{9}$ eper hr. From Fig. 1 the dose rate outside the $50 \mathrm{~cm}$ wall at 90 degrees is $5 \times 10^{-15} \mathrm{rem} / \mathrm{e}-$. For this beam loss the dose rate is $\left(5 \times 10^{-15} \mathrm{rem} / \mathrm{e}-\right) \times\left(5.4 \times 10^{9} \mathrm{e}-\mathrm{per} \mathrm{hr}\right)$ or about $0.03 \mathrm{mrem} / \mathrm{hr}$. This is below the criteria of $0.1 \mathrm{mrem} / \mathrm{hr}$ so no supplemental shielding is required for normal operation.

For accidental beam loss we have $\left(5 \times 10^{-15} \mathrm{rem} / \mathrm{e}-\right) \mathrm{x}\left(1.75 \times 10^{12} \mathrm{e}-\right)$ or a dose of 9 mrem per event. This meets the accident criteria of 10 mrem per event so no supplemental shielding is required.

\section{Roof - Injection Area}

Roof blocks in the injection area are $50 \mathrm{~cm}$ thick. To achieve $0.1 \mathrm{mrem} / \mathrm{hr}$ from normal injection losses the dose rate through the shield should not exceed $\left(10^{-4} \mathrm{rem} / \mathrm{hr}\right) /\left(3 \times 10^{11} \mathrm{e}-/ 8 \mathrm{hrs}\right)$ or $3 \times 10^{-15}$ rem/e-. From Fig. 1 the dose rate outside the $50 \mathrm{~cm}$ shield at 90 degrees is $5 \times 10^{-15}$ rem/e-. This dose rate is approximately $2 \mathrm{x}$ the criteria of $0.1 \mathrm{mrem} / \mathrm{hr}$.

For the accidental beam loss we have $\left(5 \times 10^{-15} \mathrm{rem} / \mathrm{e}-\right) \mathrm{x}\left(1.75 \times 10^{12} \mathrm{e}-\right)$ or a dose of $9 \mathrm{mrem}$ per event. This meets the accident criteria of 10 mrem per event.

The dose rate from normal injection losses exceeds the dose rate criteria by about a factor of 2 . No supplemental shielding is required at this time, however access to the area may need to be limited to trained radiation workers.

\section{Roof - Standard Area}

Roof blocks in the standard area are $35 \mathrm{~cm}$ thick. From Fig. 3 the dose rate outside the $35 \mathrm{~cm}$ shield at 90 degrees is $1 \times 10^{-14} \mathrm{rem} / \mathrm{e}-$. For the distributed beam loss of $5.4 \times 10^{9}$ e- per hr this gives a dose rate of $\left(1 \times 10^{-14} \mathrm{rem} / \mathrm{e}-\right) \times\left(5.4 \times 10^{9} \mathrm{e}-\right.$ per $\left.\mathrm{hr}\right)$ or $5.4 \times 10^{-2} \mathrm{mrem} / \mathrm{hr}$. This is below the criteria of $0.1 \mathrm{mrem} / \mathrm{hr}$.

For the accidental dose rate we have $\left(1 \times 10^{-14} \mathrm{rem} / \mathrm{e}-\right) \mathrm{x}\left(1.75 \times 10^{12} \mathrm{e}-\right)$ or about $20 \mathrm{mrem}$ per event.

The dose rate from accidental beam loss exceeds the dose rate criteria by about a factor of 2 . No supplemental shielding is required, however access to the area may need to be limited to trained radiation workers. 


\section{Ratchet Walls - Injection Area}

The ratchet walls in the injection area are $60 \mathrm{~cm}$ thick. The dose rate through the shield wall from normal injection losses should not exceed $\left(10^{-4} \mathrm{rem} / \mathrm{hr}\right) /\left(3 \times 10^{11} \mathrm{e}-/ 8 \mathrm{hrs}\right)$ or $3 \times 10^{-15} \mathrm{rem} / \mathrm{e}-$. From Fig. 2 the dose rate outside the $60 \mathrm{~cm}$ shield wall at 0 degrees and at $10 \mathrm{~m}$ from the loss point is $\left(10^{-10} \mathrm{rem} / \mathrm{e}-\right) \times(2 \mathrm{~m} / 10 \mathrm{~m})^{2}$ or $4 \times 10^{-12} \mathrm{rem} / \mathrm{e}-$. The dose rate must be reduced by $\mathrm{n}=$ $\log \left(4 \times 10^{-12} / 3 \times 10^{-15}\right)$ or about 3 Tenth Value Layers (TVLs). A TVL of 2" $\mathrm{Pb}$ is assumed. This corresponds to the attenuation in $\mathrm{Pb}$ at the Compton minimum - the minimum point in the energy absorption coefficient curve. Therefore 6" of Pb should be added as supplemental shielding to the existing $60 \mathrm{~cm}$ wall.

For the accidental beam loss at a point would result in $\left(4 \times 10^{-12} \mathrm{rem} / \mathrm{e}-\right) \times\left(1.75 \times 10^{12}\right.$ stored e- $)$ or 7 rem per event. For this we need $\mathrm{n}=\log (7000 / 10)=2.8$ TVLs of $\mathrm{Pb}$.

The normal injection losses result in a higher dose rate than the accidental beam loss scenario. Based on this it is recommended that 6 " of $\mathrm{Pb}$ be added to the $60 \mathrm{~cm}$ concrete ratchet walls in the injection area.

\section{Ratchet Walls - Standard Area}

The ratchet walls in the standard area are $50 \mathrm{~cm}$ thick. The dose rate from normal distributed losses through bend magnet ratchet walls will be relatively small. The dose rate through insertion device ratchet walls will be dominated by normally distributed losses in the insertion device straight section. Here we use the distributed beam loss of $2 \%$ over $10 \mathrm{~m}$ but we use a distance of closest approach of $15 \mathrm{~m}$ from roughly the center of the straight to a point approximately $30 \mathrm{~cm}$ from the outside surface of the shield wall. The normal beam loss as shown earlier is $\left(9 \times 10^{11} \mathrm{e}-/ 8 \mathrm{hrs}\right)$ $\mathrm{x} 10 \mathrm{~m} / 210 \mathrm{~m}$ or $5.4 \times 10^{9}$ e- per hr. From Fig. 1 the dose rate through the $50 \mathrm{~cm}$ shield wall at 0 degrees and at $15 \mathrm{~m}$ from the source point is $\left(2 \times 10^{-10} \mathrm{rem} / \mathrm{e}-\right) \mathrm{x}(2 \mathrm{~m} / 15 \mathrm{~m})^{2}=3.6 \times 10^{-12} \mathrm{rem} / \mathrm{e}-$. This gives $\left(5.4 \times 10^{9}\right.$ e- per hr $) \times\left(3.6 \times 10^{-12} \mathrm{rem} / \mathrm{e}-\right)$ or about $20 \mathrm{mrem} / \mathrm{hr}$. This requires $\mathrm{n}=$ $\log (20 / 0.1)=2.3$ TVLs of Pb.

For the accidental beam loss at the $10 \mathrm{~m}$ distance of closest approach we have $\left(2 \times 10^{-10} \mathrm{rem} / \mathrm{e}^{-}\right)$ $\left.\mathrm{x}(2 \mathrm{~m} / 10 \mathrm{~m})^{2}\right) \mathrm{x}\left(1.75 \times 10^{12}\right.$ stored $\left.\mathrm{e}-\right)=14$ rem per event. This requires $\mathrm{n}=\log (14000 / 10)$ or about 3 TVLs of $\mathrm{Pb}$.

The accidental beam loss scenario results in a more restrictive supplemental $\mathrm{Pb}$ requirement than the normal distributed losses. Based on this it is recommended that 3 TVLs (6") of Pb be added to the $50 \mathrm{~cm}$ concrete ratchet walls in the standard area.

\section{Ratchet Walls - Pb Distribution}

Supplemental $\mathrm{Pb}$ shielding of 6" is required on all ratchet walls. 
The angular width of the forward bremsstrahlung lobe is given by Swanson[4] as $\mathrm{E}_{0} \theta_{1 / 2}=100$ $\mathrm{MeV}$-degrees. For $3 \mathrm{GeV}$ thin-target bremsstrahlung this gives an angle of about $1 \mathrm{mrad}$. At $10 \mathrm{~m}$ this corresponds to a height of $1 \mathrm{~cm}$ HWHM. Assuming that the forward lobe intensity drops by half for each $1 \mathrm{~cm}$ increment then the dose rate would drop by $10 \mathrm{x}$ after $3.3 \mathrm{x} 1 \mathrm{~cm}=3.3 \mathrm{~cm}$ or a total height of about $8 \mathrm{~cm}$. Due to uncertainties in placement and electron loss assumptions it is recommended to install a belly band of 8 " total height centered about the beam height. The belly band should be 2" thick $\mathrm{Pb}$. This corresponds to stacking standard Pb bricks (2" thick x 8" high $\mathrm{x} 4$ " wide) vertically about the beam height.

Therefore, construction of all the ratchet walls should consist of 4" Pb from floor-to-ceiling and a 2" thick by 8 " high $\mathrm{Pb}$ belly band centered at e- beam height. This belly band should extend across the full width of the ratchet wall.

\section{LINAC and Booster}

Beam losses for the injection system are assumed identical to the ALS and are as follows[1]:

- $50 \%$ loss at any point in Linac,

- $20 \%$ loss at any point in Linac-to-Booster (LTB),

- $20 \%$ loss distributed in Booster at $300 \mathrm{MeV}$ or less,

- $15 \%$ distributed ramping losses at $3 \mathrm{GeV}$ in Booster.

As stated earlier, stored beam corresponds to $1.75 \times 10^{12} \mathrm{e}-/$ fill. These losses are in addition to the $25 \%$ loss upon injection into the storage ring. Therefore, the required beam current from the Linac to fill the storage ring is:

$1.75 \times 10^{12} \frac{e^{-}}{s} /(0.5)(0.8)(0.8)(0.85)(0.75)=8.6 \times 10^{12} \frac{e^{-}}{\text {fill }}$.

The conservative assumption is made that there will be 2 fills/shift and 250 shifts/year for a total of 500 fills/year. It is also assumed, as with the ALS, that any fill would require a tuneup period of $1 / 4$ intensity but four times longer than an actual fill, effectively doubling the electron beam losses for the entire injection system. This gives the following annual beam losses for the injection system: 
- LINAC - $2 \times 8.6 \times 10^{12}(0.5)(500)=4.4 \times 10^{15} \frac{e^{-}}{y r}$

- $\mathrm{LTB}-2 \times 8.6 \times 10^{12}(0.5)(.2)(500)=8.6 \times 10^{14} \frac{e^{-}}{y r}$

- Booster -

1. At $300 \mathrm{MeV}-2 \times 8.6 \times 10^{12}(0.5)(0.8)(0.2)(500)=7.0 \times 10^{14} \frac{e^{-}}{y r}$

2. At $3 \mathrm{GeV}-2 \times 8.6 \times 10^{12}(0.5)(0.8)(0.8)(0.15)(500)=4.2 \times 10^{14} \frac{e^{-}}{y r}$

For the Booster, the radiation shielding is dictated by the beam loss at full energy. Often injection beam losses are not uniform around the ring but instead more concentrated in a localized area. In order not to underestimate the required shielding the high-energy Booster losses are assumed to be lost at any point in the Booster. Fig. 4 gives the dose rate as a function of shield thickness at energies of $100 \mathrm{MeV}$ and $3 \mathrm{GeV}$ for beam loss at a point. For the Booster a dose rate of $0.2 \frac{r e m}{y r} / 4.2 \times 10^{14} \frac{e^{-}}{y r}=4.8 \times 10^{-16} \frac{r e m}{e^{-}}$must be achieved. From this figure a minimum required thickness would be about $95 \mathrm{~cm}$. For conservatism it is recommended that the walls be $100 \mathrm{~cm}$ and the roof $80 \mathrm{~cm}$ when taking into account the relatively low (25\%) occupancy.

For the Linac at $100 \mathrm{MeV}$ the required dose rate would be $0.2 \frac{\mathrm{rem}}{\mathrm{yr}} / 4.4 \times 10^{15} \frac{e^{-}}{\mathrm{yr}}=4.5 \times 10^{-17} \frac{\mathrm{rem}}{e^{-}}$. From the same figure, at $100 \mathrm{MeV}$, this would require a minimum of approximately $70 \mathrm{~cm}$.

Since the Linac and Booster injection system is only required to be used for filling the storage ring a small fraction of the time and experience at other light sources has shown that this injection system may therefore find other unexpected uses, it is prudent to be conservative in shielding this area. It is therefore recommended that the entire injection area (Booster + Linac) be shielded with normal density concrete walls $100 \mathrm{~cm}$ thick and roof $80 \mathrm{~cm}$ thick.

\section{References}

[1] A. Jackson, personal communication, Lawrence Berkeley National Laboratory, Berkeley, CA.

[2] T. M. Jenkins, "Neutron and Photon Measurements Through Concrete from a 15 GeV Electron Beam on a Target - Comparison with Models and Calculations", Nucl. Instrum. Methods 159 (265) 1979.

[3] H. dinter and K. Tesch, "Dose and Shielding of Electron Photon Stray Radiation from a High Energy Electron Beam", Nucl. Instrum. Methods 143 (349) 1977.

[4] W. P. Swanson, "Radiological Safety Aspects of the Operation of Electron Linear Accelerators", Technical Report Series Number 188, IAEA, 1979.

[5] A. H. Sullivan, "A Guide to Radiation and Radioactivity Levels Near High Energy Particle Accelerators", Nuclear Technology Publishing, 1992. 


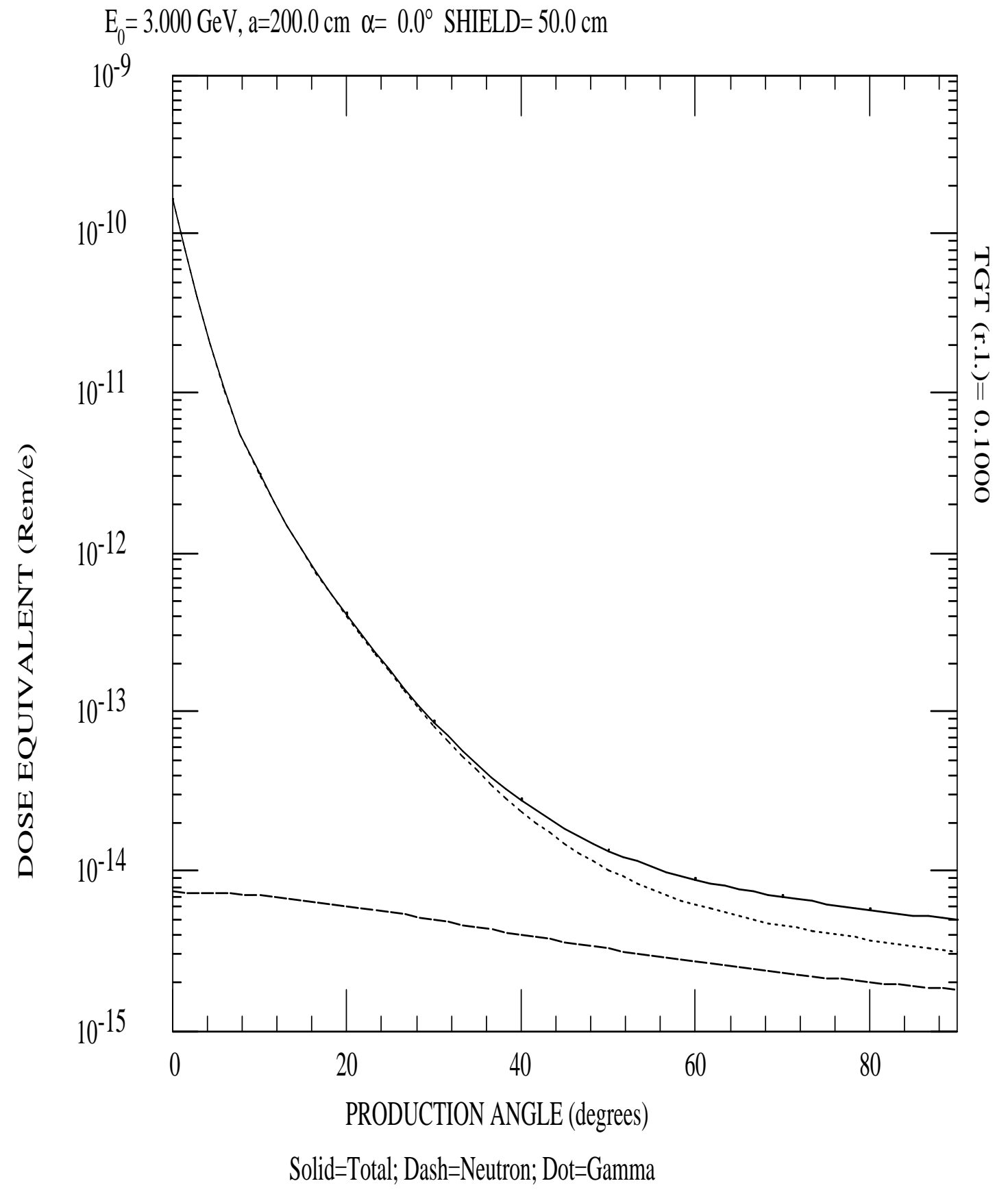

Figure 1: Dose rates through a $50 \mathrm{~cm}$ concrete wall. 


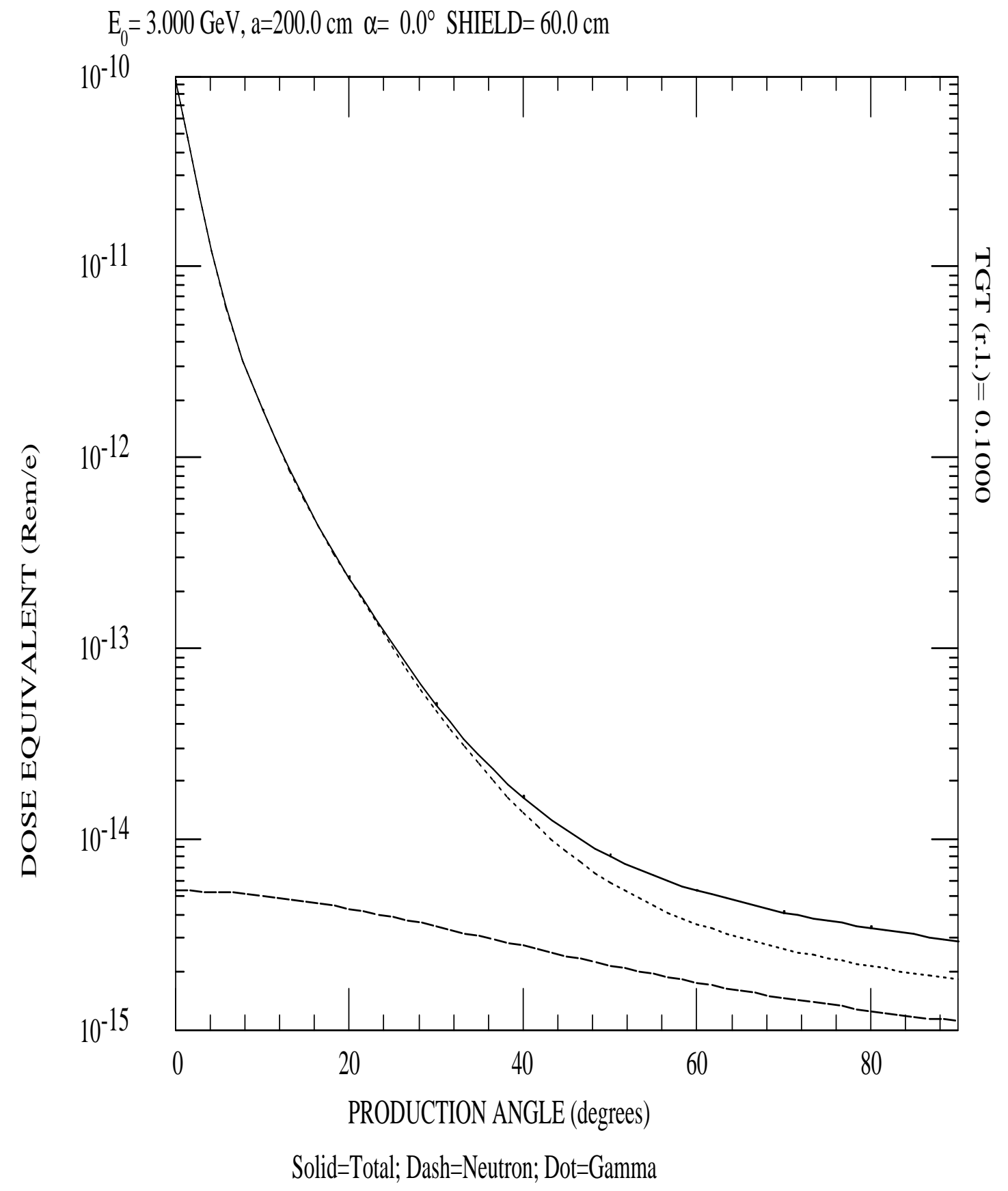

Figure 2: Dose rates through a $60 \mathrm{~cm}$ concrete wall. 


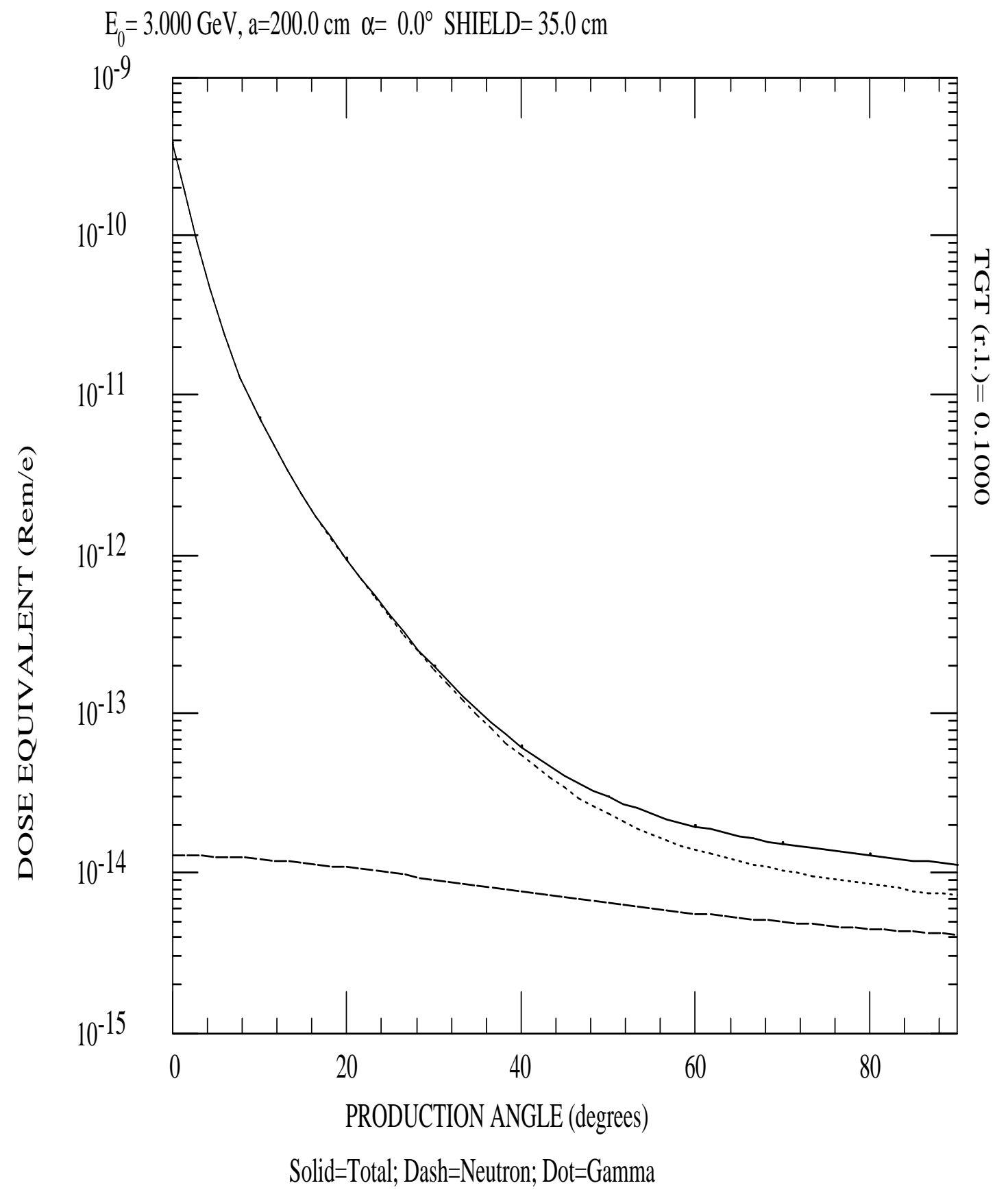

Figure 3: Dose rates through a $35 \mathrm{~cm}$ concrete wall. 


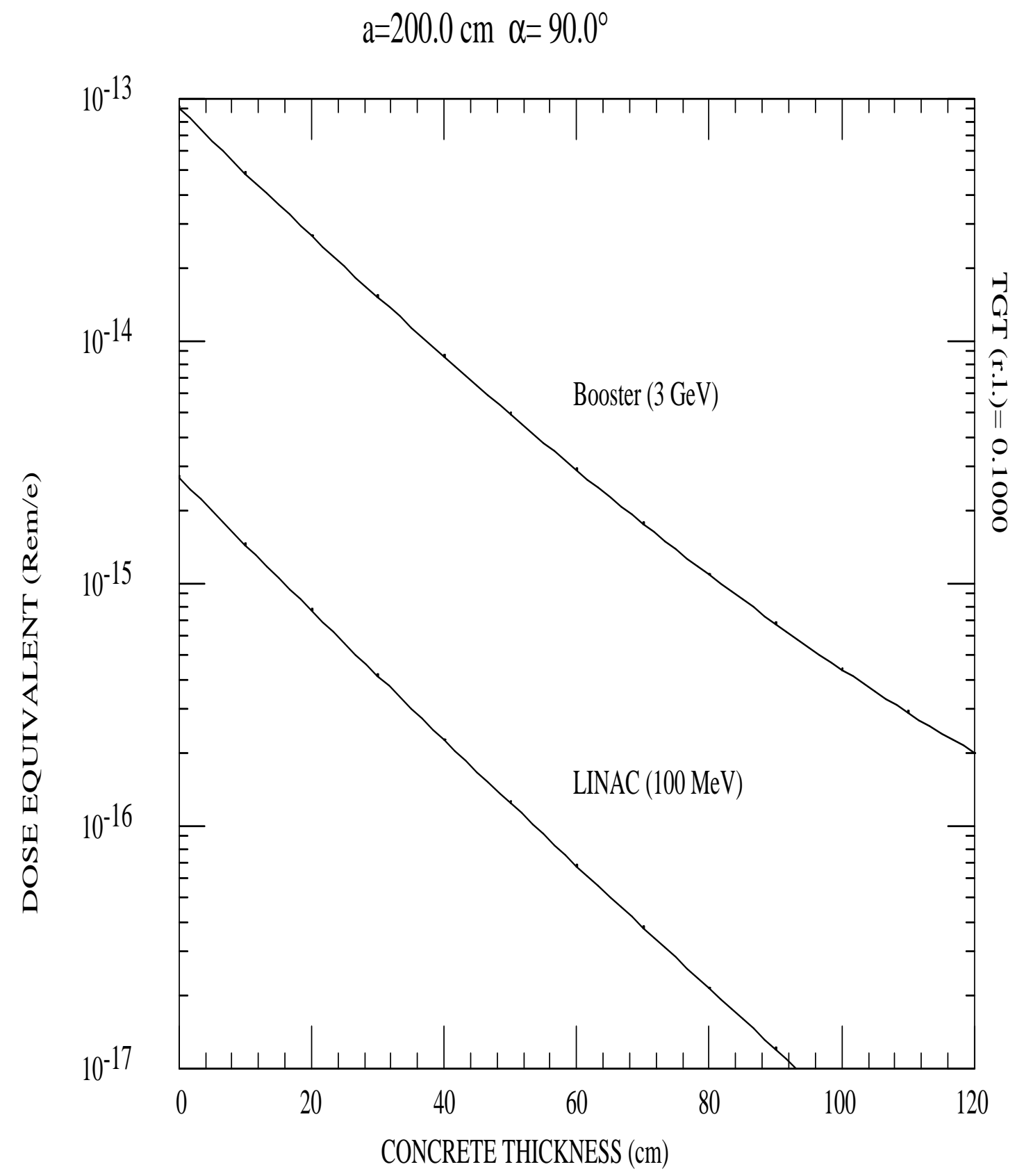

Figure 4: Dose rate as a function of shield thickness for beam loss at $100 \mathrm{MeV}$ and $3 \mathrm{GeV}$. Dose rate is calculated at 90 degrees from beam loss point. 